\title{
THE EVOLUTION OF ELECTRONIC MARKETPLACES: AN EXPLORATORY STUDY OF INTERNET-BASED ELECTRONIC COMMERCE WITHIN THE AMERICAN INDEPENDENT INSURANCE AGENCY SYSTEM
}

\author{
Andrew F. Burton \\ Andersen Consulting \\ Chicago, Illinois \\ USA \\ John G. Mooney* \\ The Michael Smurfit Graduate School of Business \\ University College Dublin (National University of Ireland, Dublin) \\ Carysfort Avenue, Blackrock, Dublin, Ireland. \\ * Correspondence should be addressed to Dr. John Mooney
}

\begin{abstract}
Evolving competitive, organisational and technology environments drive organisations to continually evaluate how information technology resources can be exploited for competitive value. The emergence of a global information infrastructure has spawned an entirely new area for competitive exploitation, electronic marketplaces.

This paper first presents a review and synthesis of the conceptual and empirical literature on electronic marketplaces. Drawing upon multiple theoretical perspectives, we develop a framework for analysing their potential influences on market and industry structure. This conceptual framework is then applied to an empirical assessment of the potential of the Intemet as an electronic marketplace for the American Independent Insurance Agency System.

"It was no accident that salesmanship had a renaissance in the merchandising of insurance, the invisible commodity. For insurance was complicated and required detailed explanation to everybody, but especially to the democratic millions who in America would have the opportunity to become insurance customers... the abstract and complex qualities of insurance together with its intimate and personal aspects, contimued to keep it as a last preserve for the salesman against advertising"

Daniel Boorstin, Librarian of Congress
\end{abstract}

\section{INTRODUCTION}

Coase (1937:22) defines the firm as consisting of "the system of relationships which comes into existence when the direction of resources is dependent on an entrepreneur". For over half a century, scholars have followed Coase's insight into the nature of the firm by recognising firms as collections of activities that are coordinated together to produce, market, deliver, and support the firm's product or service (Williamson 1975; Porter 1985; Hines 1993). The manner and structure through which a firm manages its relationships with its buyers and suppliers form its value system.

The implementation of value systems was partly facilitated by the development of information systems that cross organisational boundaries. Inter-organisational information systems, first described by Barrett and Konsynski (1982), electronically link firms to their suppliers and distributors. Reported benefits from inter-organisational systems include increased efficiency of order processing, reduced costs from just-in-time inventory management, locking in trading partners through network participation, customisation of products and services, improved coordination at the interface between the customer and supplier, improved organisational efficiency, better information management, and lower overall co-ordination costs (Bakos 1991; Steinfield, Kraut and Plummer 1995). These electronic interactions provided the early foundation for electronic marketplaces.

Within the broader sphere of electronic commerce, advancements in information technology have influenced the different mechanisms that co-ordinate the flow of information and commerce. Williamson (1975) proposed that firms exist to reduce the cost of negotiating, monitoring and executing transactions that are required to acquire goods and services in the open market, with the distinction between a market and a hierarchy based on the economic location of production. Firms choose vertical integration to control transaction processes when transactions costs are excessive while choosing to participate in markets when transaction costs are low (Nouwens and Bouwman 1995).

With the introduction of computing and communications technologies into the processes through which firms manage and co-ordinate their transactions, traditional hierarchical and market co-ordination mechanisms are affected, culminating in electronic hierarchies and electronic markets (Malone, Yates and Benjamin 1989). Bakos (1991) defines an electronic hierarchy as an electronic link that serves as a tool for bilateral information sharing and defines an electronic market as a market system that allows buyers and sellers to exchange information about market prices and product offerings, thus representing an investment in multilateral information sharing. As the presence of electronic hierarchies and electronic markets has increased in the commercial environment, different theories have emerged to explain their use and future direction. 
The Electronic Markets Hypothesis (EMH) predicts that the effect of technology on market mechanisms will increase the proportion of economic activity coordinated by markets, with a shift from hierarchies (Malone, Yates and Benjamin 1987). The theory states that advances in computing and communications technology will facilitate an evolution from electronic hierarchies, through biased and unbiased electronic markets, to a personalised electronic market. ${ }^{1}$ Examples offered by Malone et al. to support the EMH include airline reservation systems, and companies such as IBM, Xerox, and General Electric $(1987,490)$.

The Move to the Middle Hypothesis (MMH) offers a refinement on the EMH. The MMH recognises advances in computing and communications have affected the costs of co-ordination in which value chain restructuring will be characterised by increased outsourcing and an emphasis on close, long term relationships with suppliers (Clemons, Reddi and Row 1993). In short, the MMH predicts the movement of activity along the electronic hierarchies/markets spectrum will be towards the middle of the spectrum. Thus, the reduction in transaction costs will not cause an increase in the optimal number of suppliers, rather buyers and suppliers will work closer together and develop longer term relationships.

In limiting the number of suppliers, a firm can be motivated by Non-contractible Investments, such as quality, responsiveness, trust, information sharing and innovation (Bakos and Brynjolfsson 1993). It has been proposed that information technology investments are increasingly becoming non-relationship specific, and thus, will be made with fewer suppliers and for longer time periods due to economies of scale, incentives to suppliers, reduced benefits of search, return on investment, learning curve effects and other incentives (Clemons, Reddi and Row 1993). Bakos and Brynjolfsson (1993) found that although information technology has reduced costs and theoretically allows for more suppliers, the benefits gained by closer buyer-supplier relationships offset the possible benefits of more suppliers (1993). These relationships of few suppliers with increased co-operation and interaction between buyers and suppliers have emerged as value-adding partnerships (Clemons, Reddi and Row 1993).

\section{ELECTRONIC MARKET CHARACTERISTICS}

To understand the cost factors that buyers consider when participating in electronic marketplaces, it is necessary to consider electronic market characteristics. The above mentioned theories (EMH and MMH) attempt to address the business issues organisations face when trying to develop electronic links to buyers and suppliers. Along with the logistical and strategic issues, it is important to consider market conditions, specifically whether the organisation is participating in a commodity or differentiated market conditions. Bakos (1991b) examined how buyers behave when they search for sellers in commodity and differentiated markets. Commodity markets are characterised by identical products offered by like sellers, whereas differentiated markets are more common because they offer a variety of different product offerings to meet the wide range of buyer needs and preferences. In a commodity market, buyers will typically choose the product offered at the lowest cost (including search, transportation and other related costs). Commodity markets reveal the following characteristics (Bakos 1991b, 298-299):

- seller prices decrease as the cost of search decreases

- the amount of search increases as the cost of search decreases

- the amount of search increases as seller prices become more dispersed

- ceteris parabus, as seller prices become more dispersed, buyers' total costs decrease

With the introduction of technology into a commodity market and the creation of an electronic marketplace, the ability of buyers to search is increased. Thus, the distribution of price and product information can become more efficient and effective.

In differentiated markets buyers consider the various price and product offerings available, and determine the product's ability to adequately match their needs. A number of differences exist separating a differentiated market from a commodity market, including (Bakos 1991b, 300-301):

- "...consumer preferences determine the location of their ideal product or product mix"

- "...the heterogeneity of consumers and product offerings is central to the ability of sellers to exploit buyer search costs and thus extract monopolistic rents"

- "...electronic market systems providing product and price information may generate substantial allocational efficiencies by enabling customers to locate suppliers that better match their needs"

${ }^{1}$ In a biased market the information in the system and/or the system structure favors a particular organization or person, whereas in an unbiased system the information and system structure are unbiased towards the market participants. A personalized electronic market provides customized information tailored to the system user's needs. 
A buyer's search process is very complex with product offering and search cost factors interacting differently. However, with the introduction of information systems into a differentiated market to create an electronic marketplace, it is suggested substantial impacts and potential changes occur to organisational and market structures.

The introduction of Agency Theory (i.e. the recognition that the operation of a market is not costless, as is assumed in classic economic literature, and consequently that a firm can be a substitute for the market mechanism created to reduce the costs of transactions) shows that a large amount of a firm's costs are related to the acquisition and processing of information and can therefore be reduced by application of information technologies (Gurbaxani and Whang 1991, 71). Thus, with the introduction of organisational information systems, firms not only have the potential to reduce internal costs, but can also, with the development of customer based inter-organisational information systems, improve their ability to access a wider range of buyers due to reduced buyer search costs.

As discussed previously, whether the seller is participating in a differentiated or commodity market influences the manner through which buyers search for a product or product mix. The role of an information system to distribute product/service and price information through an electronic market can serve to improve allocational efficiencies and decrease overall cost.

Allocational efficiencies and cost reductions are attributed to three distinct affects information technology has on organisational and market structure (Malone, Yates and Benjamin 1987, 488-489):

1. electronic communication effect - information technology can allow more information to be communicated in the same amount of time while decreasing the costs of this communication dramatically.

2. electronic brokerage effect - electronic markets, by electronically connecting many different buyers and suppliers, can assist the matching of buyer preferences and supplier characteristics, thus increasing the number of alternatives that can be considered, increasing the quality of the alternative eventually selected, and decreasing the cost of the entire product selection process.

3. electronic integration effect - information technology can be used not just to speed communication but to also change the processes that create and use the information.

The three electronic effects described by Malone et al. contribute towards illustrating how information systems, deployed and used to create an electronic marketplace, have the potential to improve organisational and industry efficiency and reduce costs. Two factors are noted to influence the utilisation of the electronic marketplace and its development as either a hierarchy or a market. "Two... more specific factors that can be changed by information technology are important in determining which co-ordination structures are desirable: asset specificity and complexity of product description" (Malone, Yates and Benjamin 1987, 486). ${ }^{2}$

These factors are suggested to influence whether a product or service is biased towards participating in an electronic market or an electronic hierarchy. It has been proposed the more complex and asset specific a product or service the more likely it will be suited for an electronic hierarchy rather than an electronic market.

Assuming a product or service is suited for an electronic marketplace, the types of characteristics an electronic market demonstrates are important for the seller to understand and manage. Bakos (1991, 1991b) identifies certain characteristics of electronic markets:

- reduction in buyer search costs and increased ability to search for product or product mix information and price

- promotion in price competition among sellers

- reduction in supplier market power

- reduction in buyer search time

- reduction in seller time to communicate product and price information

- the benefits of participation in the electronic market increases as participants increase

- participants are influenced by costs that could be incurred by switching from one electronic market to another

- large amounts of initial capital investment required for participants

- the benefits for market participants are uncertain

- the electronic market offers economies of scale and scope

- the timetable for change in an electronic market is uncertain

2 Asset specificity includes site (whether a resource can be moved), physical (a tool or resource designed for a single purpose), human (a physical or mental skill that can not be readily applied to another purpose), and time (its value is highly dependent on a specific time period of use). Complexity of product description refers to the amount of information needed to specify the attributes of a product in enough detail to allow potential buyers to make a selection. 
Along with the market characteristics previously described, other network attributes interact to influence the promotion and use of hierarchical and market structures (Steinfield, Kraut and Plummer 1995), including:

- in addition to multiple buyers and suppliers, a need exists for some form of third party market maker to create a network to facilitate search and product/service matching

- the network's ability to allow rich product descriptions for complex products

- network openness to allow easy communication with new participants, public protocols widely accepted and adopted by market participants, widespread participation, and low costs for new entries onto the network

- the extension of open networks to end consumers to support electronic markets

- public networks reduce the constraints on connecting uncertain, low volume trading partners or potential partners

The characteristics and attributes of electronic networks have been forwarded to help practitioners and researchers understand the nature an electronic market and related environmental conditions. Such an understanding not only furthers the research into electronic marketplaces, but also assists in providing a strategic perspective in which to assess electronic markets.

\section{MARKET INTERMEDIATION AND DISINTERMEDIATION}

It is widely argued that an inevitable effect of electronic commerce will be disintermediation (i.e., removal of the "middlemen"). However, other claims have been made that electronic commerce will not result in disintermediation, rather intermediation will continue to prosper and provide a valuable role in electronic commerce.

The importance of understanding electronic markets and their effects is increased when one examines how they influence organisational functions and decision processes, also known as the decision to either "make or buy." Transaction Cost Theory (TCT) states that a firm has two options for organising its economic activities: the internal hierarchy of vertically integrated processes of the organisation, or the reliance on external organisations in the open market to perform business processes (Coase 1937, Williamson 1975). With the link of TCT to electronic markets (Malone, Yates and Benjamin 1987), researchers have argued that as costs are reduced by information systems, the systems can be extended to reach end consumers (Benjamin and Wigand 1995). Thus, with the introduction of inter-organisational systems and the creation of electronic markets the manner through which industries are structured and firms relate to buyers and suppliers is questioned.

Researchers have attempted to understand the role intermediaries will have in inter-organisational systems as they emerge into electronic marketplaces. Benjamin and Wigand (1995b) and Thornton (1994) explore how industry value chains and transaction patterns can be affected by electronic markets (Figure 4.1). In a digital environment, producers originally limited to a distribution network of wholesalers and retailers, can bypass those members of the value chain to directly interact with members further down the chain or sell directly to end consumers.

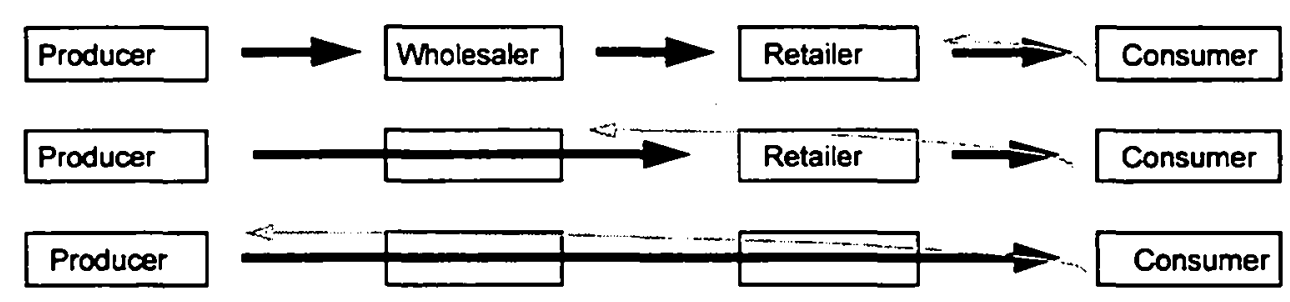

Figure 1 Value Chains and Transaction Patterns

Source: Adapted from Benjamin and Wigand (1995b): "Electronic Markets and Virtual Value Chains on the Information Superhighway", Sloan Management Review, Winter, 62-72, and Thornton (1994): "Revolution in Japanese Retailing", Fortune Magazine, February, 144

Some researchers have explored why and how producers will attempt to directly interact with end consumers. Sarkar, Butler and Steinfield summarise the research best by stating, "...one fundamental question, therefore, is to what extent producing organisations would take advantage of direct electronic links with consumers, and whether in the process, intermediaries will be eliminated from the value system" $(1995,3)$. 
Benjamin and Wigand (1995) clearly state that market intermediaries are threatened by the National Information Infrastructure (i.e. an electronic market) because of market benefits, "...consumers will choose alternative forms of transactions in favour of price, high quality, selection choice, and time savings" (1995b, 70).

The Threatened Intermediary Hypothesis (TIH) states that an electronic market network can be extended to directly link consumers with producers, and in doing so, lower transaction costs producers incur when marketing and selling to end consumers (Sarkar, Butler, and Steinfield 1995). For example, in a three member value system (Figure 4.2), possible transaction costs and intermediary value dictate which channel a producer uses to market and sell products for consumption. If the cost of transaction one (T1) is more than transaction two (T2) and transaction three (T3) combined, than the intermediary is valued and used. However, if the cost of T1 is less than $\mathrm{T} 2$ and $\mathrm{T} 3$ and the market value of the intermediary is not needed, than the intermediary is bypassed.

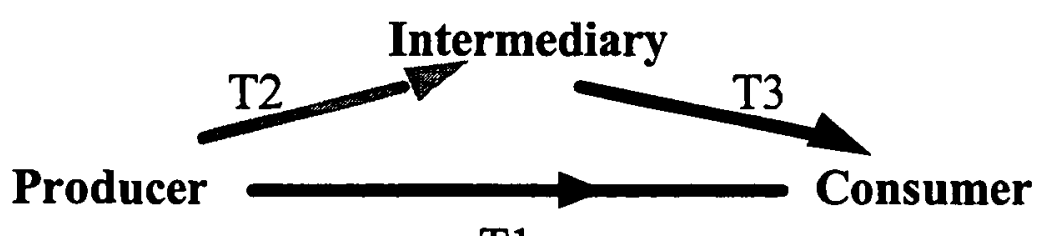

$\mathrm{T} 1$

Figure 2 Value System Transaction Patterns

Source: Adapted from Sarkar, Mirtra B., Brian Butler and Charles Steinfield (1995): "Intermediaries and Cybermediaries: A Continuing Role for Mediating Players in the Electronic Marketplace", Journal of Computer Mediated-Communication, 3, 1-17 [URL:http://jcmc.huji.ac.il]

Benjamin and Wigand noted the threat of disintermediation to market participants by stating, “...all the stakeholders in an industry value chain must consider whether their place in the chain is threatened and, if so, what long term strategies to experiment with" (1995b, 71). However, “...rather than the highly abstracted view of intermediaries as providing a single unified service known as 'co-ordination', the roles of intermediaries must be considered in more detail in order to understand the impact of the NII (i.e. an electronic market)," including the following multifaceted functions (Sarkar, Butler and Steinfield 1995, 7-11):

- Search and Evaluation

- Needs Assessment and Product Matching

- Customer Risk Management

- Product Distribution

- Product Information Dissemination

- Purchase Influence

- Provision of Customer Information

- Producer Risk Management

- Transaction Economies of Scale

- Integration of Consumer and Producer Needs

Bakos and Bailey $(1997,2-4)$ also addressed the issue of market value provided by market intermediaries and noted intermediaries provided the following five functions:

- aggregate buyer demand or seller products to achieve economies of scale or scope and to reduce bargaining asymmetry

- protect buyers and sellers from opportunistic behaviour of other participants in a market by becoming an agent of trust

- provide marketing information to suppliers

- facilitate the market by reducing operating costs

- match buyers and suppliers

With the advancement of multidimensional functions as added value intermediaries provide in an industry value system, a more in-depth analysis and understanding is needed to understand how electronic markets can lower transaction costs and support value adding functions previously provided by market intermediaries, or the possibility that new intermediary roles and value added functions will emerge for market participants. Sarkar, Butler and Steinfield suggested "...not only is it likely that widely available information infrastructures will reinforce the position of traditional intermediaries but the networks will also promote the growth of a new generation of intermediaries" $(1995,1)$. 
Sarkar, Butler and Steinfield argued intermediation will continue to provide a valuable role in industry value systems, and their analysis suggested electronic markets can lead to four possible outcomes (Figure 4.3): a reinforcement of existing direct producer to consumer links, the use of an electronic market by producers to bypass intermediaries and link directly to consumers, a reinforcement of existing intermediary structures, or the emergence of new electronic market based intermediaries (1995). The four outcomes model (Figure 4.3) is based on transaction costs and intermediary value (Figure 4.2).

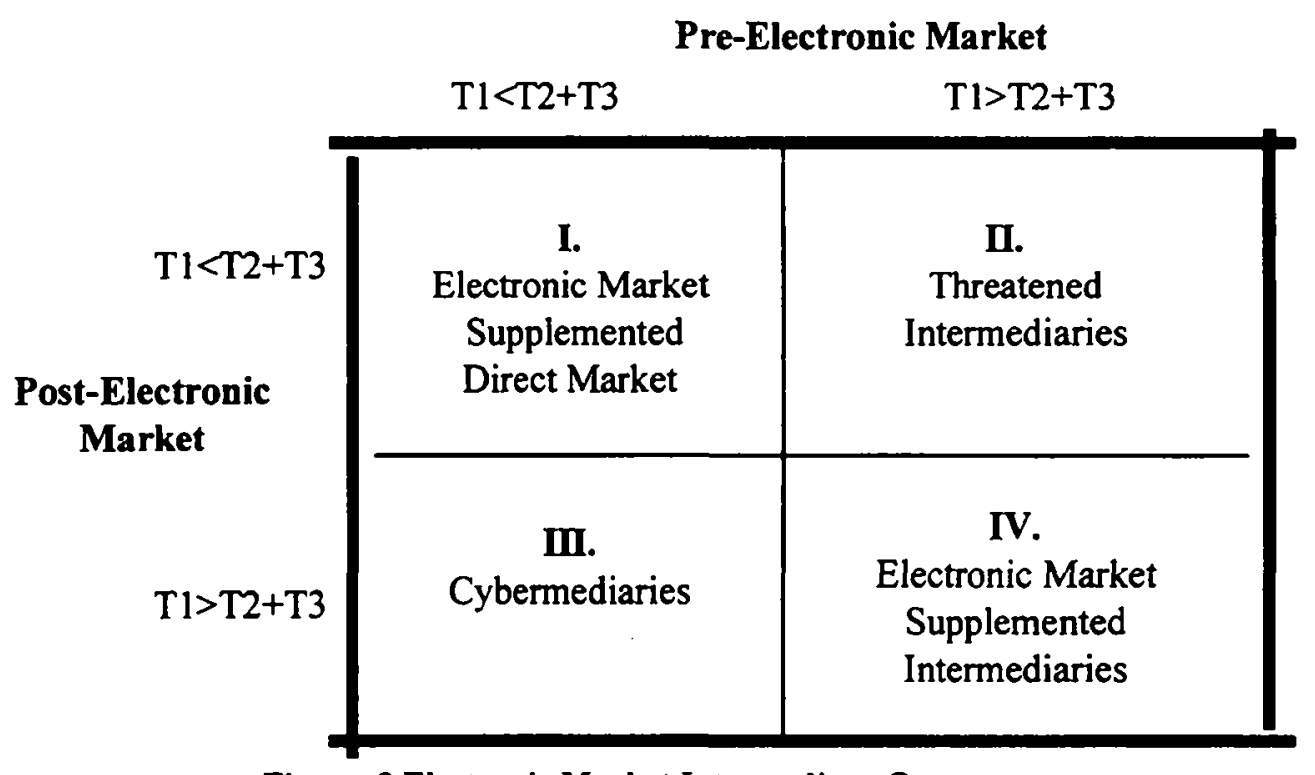

Figure 3 Electronic Market Intermediary Outcomes

Source: Adapted from Sarkar, Mirtra B., Brian Butler and Charles Steinfield (1995): "Intermediaries and Cybermediaries: A Continuing Role for Mediating Players in the Electronic Marketplace", Joumal of Computer Mediated-Communication, 3, 1-17 [URL:http://jcmc.huji.ac.il/]

An interesting possible outcome was noted in which scenario III would occur where a pre-electronic market structure consisted of direct relationships but in a post-electronic market the emergence of cybermediaries occurred to take advantage of electronic market opportunities (Sarkar, Butler and Steinfield 1995).

The ability to link directly with consumers not only has the potential to threaten intermediaries, it also has the potential to negatively impact sellers. Formal support for this claim has been developed (Bakos 1996, 1991), with potential impacts including:

- promotion of price competition

- reduction in market power of sellers

- passage of system benefits from sellers to buyers

- creation of more demanding customers less likely to compromise on preferred products/services

Academic researchers have suggested the following strategies and suggestions to anticipate and respond to the negative impacts of electronic markets (Bakos 1996, 1991, 1991b; Malone, Yates and Benjamin 1987, 496-497):

- seller control of the type of system introduced

- development of a system that emphasises product information not price information

- obtain early mover advantage to establish market leadership and obtain large market share

- increase product/service differentiation to make it difficult for buyers to compare prices and product offerings (also increases buyer search costs)

- sellers or developers of electronic markets should not expect indefinite competitive advantages from the system

- improve underlying economies of scale by leveraging development expertise, installed networks, customer bases and proprietary databases

- assess the point of customer contact to determine its ability to serve as a critical resource to determine electronic market benefits, participation and sustainability of profits

With the emergence of such proposed negative impacts of electronic markets on sellers and intermediaries, researchers have questioned the motives for organisations and individuals to establish such markets. The theory of the prisoner's dilemma that sellers as a group do not benefit from an electronic market system, but as individuals the revenues that can be generated from such a system can be beneficial and outweigh the losses, 
assists in explaining business motivations for electronic market makers (Bakos 1991). Such market makers have been suggested to pursue revenue generation and increased market growth at the expense of the industry as a whole. As electronic market usage and utilisation improves by different industry participants the likelihood of electronic market participation becoming a strategic necessity and an integral part of industry infrastructure increases (Bakos 1991, 308).

Additionally, market makers often have an opportunity to create a system biased towards a given product or firm. As noted by Benjamin and Wigand, "...if a market maker owns or has a substantial interest in any suppliers, it can bias the market in their favour and both the consumer and other suppliers will be disadvantaged" $(1995,11)$. Benjamin and Wigand also suggest the overall market maker effect was a "...phenomenon in which the consumer does very well, producers lose their profit margins, and the market makers gain the remaining profits" (1995b, 66).

Finally, as noted by Bailey and Bakos, "...a newer paradigm of customised goods, reduced delivery time, and greater customer satisfaction may be more difficult to measure, but may be the one appropriate to use for electronic markets" $(1997,13)$.

\section{THE AMERICAN INDEPENDENT INSURANCE AGENCY SYSTEM}

The emergence of independent insurance agents in the United States began between 1795-1796 when insurance companies experimented with the appointment of exclusive agents (Payan 1993, 2). Mehr and Cammack (1980) recognise an insurance agent as anyone authorised by an insurer to solicit, create, modify, or terminate contracts of insurance between the insurer and the insuring public, and includes the following characteristics $(1980,99$. 101):

- an agency relationship is established between principals and agents by mutual assent given in an express agreement known as an agency contract

- an ability to establish a presumptive agency in which an insurer's behaviour causes a reasonable person to believe that an individual is an agent of the company

The costs of agent services are covered from the premiums paid by insureds, with differences in premium levels based on differences in agency services provided to the consumer. Insurance distribution costs are reduced by shifting part of the servicing burden to consumers where they determine how much service they wish to buy and supply for themselves (Mehr and Cammack 1980, 554).

Marketing insurance company products can be done through various distribution channels, including the agency system which relies on agents to sell the insurance products, direct selling in which insurers write business directly to consumers, and mass merchandising in which selling and underwriting is conducted in a group or collective basis (Mehr and Cammack 1980, 565). The focus of this paper will be the American agency system where companies use independent agents to market and sell insurance products and services. 3

A majority of property and liability insurers in the United States currently operate in the American Independent Agency System, in which:

- insurers operating in the system are independent agency insurers

- agents are independent from companies and can represent multiple insurers

- agents issue policies, collect premiums, and retain exclusive rights to solicit renewals from customers

A white-paper for the National Association of Insurance Commissioners (NAIC) found the Internet as a convenient way for consumers to learn about insurance products, sources, and pricing; the marketing of insurance over the Internet offers insurance regulators an additional opportunity to monitor insurance market conduct; and a means for companies to use a new distribution channel which could incorporate all facets of an insurance transaction (N.A.I.C. 1997)

The NAIC has suggested the Internet serves four functions for the insurance industry (NAIC 1997):

1. Single Source Sales Site- in which a single insurance company markets its products and services over the Internet though a WWW homepage; has the ability to allow consumers to purchase insurance directly from the company and provide on-line requests for quotes; and offers a medium for companies to work with agents to educate and sell to consumers

2. Insurance Malls- offers a site where sellers from within one industry or across multiple industries can market and sell their insurance products and services

\footnotetext{
${ }^{3}$ At present there are three main sources for insurance in the US: captive agents who can sell insurance for only one company, telephone insurance representatives who can offer insurance of one company, and only over the telephone, and independent insurance agents who represent multiple insurance companies and provide insurance products based on price, coverage, and service.
} 
3. Internet Insurance Servicing-providing full servicing capabilities to the insurance consumer during all facets of the insurance transaction

4. Company Agent Communications to serve as a tool to enhance insurance company and agency communication and information exchange

In addition to the four possible Internet functions serving the industry, the NAIC suggests the Internet provides consumers, regulators, and the industry with a number of advantages and disadvantages (Table 1).

Table 1 Internet Insurance Advantages and Disadvantages

\begin{tabular}{|c|c|c|}
\hline Insurance Segment & Advantages & Disadvantages \\
\hline Consumers & $\begin{array}{ll}\text { - } & \text { product and information } \\
\text { accessibility } \\
\text { - . } \\
\text { - } \\
\text { - } \\
\text { - } \quad \text { lowent \& product search } \\
\text { losts }\end{array}$ & $\begin{array}{l}\text { - lack of personal interaction } \\
\text { - unfamiliarity with laws \& } \\
\text { regulations } \\
\text { - potential lack of market } \\
\text { access }\end{array}$ \\
\hline Regulators & $\begin{array}{l}\text { - electronic access to } \\
\text { consumers and industry } \\
\text { sales and solicitation } \\
\text { electronically monitored }\end{array}$ & $\begin{array}{l}\text { potential lack of market } \\
\text { access } \\
\text { - } \quad \text { explosive growth in use } \\
\text { without adequate resources } \\
\text { - } \quad \text { regulatory overview } \\
\text { problems } \\
\text { - increased fraud }\end{array}$ \\
\hline Industry & $\begin{array}{l}\text { - } \\
\text { and transactions } \\
\text { reduced administrative and } \\
\text { operating costs } \\
\text { - } \quad \text { target market opportunities } \\
\text { improved matching of needs } \\
\text { with products }\end{array}$ & $\begin{array}{l}\text { - } \\
\text { compliance } \\
\text { - } \quad \text { physical market access to } \\
\text { emerging markets } \\
\text { - } \quad \text { solicitation violations } \\
\text { - } \\
\text { applicant qualification for } \\
\text { insurance } \\
\text { advertising laws and } \\
\text { regulations }\end{array}$ \\
\hline
\end{tabular}

Source: Adapted from National Association of Insurance Commissioners (NAIC)(1997): The Marketing of Insurance Over the Internet, Draft: June 4

A number of recent insurance industry movements indicate the Internet is having a profound impact on how different organisations are preparing for the future, including;

- the Independent Insurance Agents of America web site connects to WWW homepages for more than 22,000 independent agencies on the Internet (Banham 1997)

- InsWeb [www.insweb.com], a year old company that intends to offer web-based comparative shopping of insurance products and quotes and has invested at least $\$ 10$ million into its web site, and QuickQuote, are building a presence on the Internet and recruiting organisations to participate in their services (Brandel 1996, Halper 1997)

- Internet technological advances are offering insurance companies opportunities to cut their distribution margins by $15-18$ percent (Higgins 1996)

- $\quad$ six insurance companies have created an alliance, know as the World Insurance Network, to build a virtual private network with secure Internet "hooks" that will enable them to exchange e-mail and provide the foundation for electronic commerce (Cole 1997)

\section{RESEARCH METHODOLOGY}

This paper aims to identify whether emergent evidence of the following electronic market attributes and effects exist within the context of Internet-enabled markets in the Insurance sector:

- Electronic Communication Effect

- Electronic Brokerage Effect

- Electronic Integration Effect 
- Effect of Product Characteristics

- Impact on Market Structure and Process

- Economics of Market Participation

Due to the early stage of theory building in this area, the research questions were explored through qualitative research categorised as theory building case studies in which constructs and propositions emerge inductively through the process of fieldwork (Eisenhardt 1989, Swamidass 1991). While inductive theory building from case studies increases the likelihood of generating novel theory, Eisenhardt (1989) identifies several possible weaknesses. To offset potential methodology weaknesses a number of steps were taken:

- constructs and propositions studied were obtained from previous conceptual and empirical research regarding electronic markets

- these were used to develop an interview guide containing a set of exploratory and qualitative questions, supplemented by open-ended questions

- initial testing of interview guides was conducted with insurance industry experts from the Independent Insurance Agents of America, Inc.

- the targeted sample was obtained from participation and invitation lists from past industry events and conferences related to electronic commerce, the Internet and the Independent Agency System

- targeted respondents were senior and executive managers with direct involvement in Internet related insurance issues

- organisations contacted participated in a broad spectrum of markets with national, regional and local business concerns

- information gathered was collected through extensive telephone interviews and follow-up conversations

- in order to reduce respondent bias and response error, information collected was not attributed or recorded as individual or organisational specific

- interview results were reviewed with respondents to ensure factual consistency

\section{Sample Selection}

As previously mentioned, to assist in reducing possible weaknesses in the study the sample population was chosen from insurance companies (carriers) participating in the American Independent Insurance Agency System. These insurance carriers use independent insurance agents to distribute, market, and sell their products were chosen due to their position in the industry value chain. The perspective of insurance carriers was deemed to be particularly valuable due to their ability to potentially change distribution channel methods should market and competitive forces change. Also, the companies targeted have all created a presence on the World Wide Web.

To identify key informants with knowledge of insurance, the independent agency distribution channel, electronic commerce and the Internet, respondents were selected from relevant industry event and coalition lists. Respondents were senior and executive level managers with direct involvement in Internet related insurance issues from established, well-rated insurance organisations with substantial asset levels firms participating in a range of markets with national, regional and local business concerns.

\section{Data collection}

To facilitate maximum participation in the study from the sample population numerous steps were taken. Pretesting, relying on colleagues, respondent surrogates, or actual respondents to evaluate and refine the interview guide, was conducted to examine respondent interest, meaning, question transformation, continuity and flow, question sequence, skip patterns, variability, and length (Cooper and Emory 1995, 317-321).

Study respondents were contacted over the telephone to confirm their ability to provide adequate target data. Initial telephone contact consisted of a brief introduction, the purpose of the study, estimated time for the interview and a summary of topics to be covered during the interview. Specific appointments were made with the respondents to arrange for an appropriate interview time and setting.

On subsequent contact to conduct the interview, the respondents were reminded of the purpose and nature of the study, and topics to be discussed. Before starting the interview the researcher asked respondents if they had any comments or questions regarding the process. During a three week time period a total of 19 respondents from 17 organisations were interviewed for one hour each. Following the interviews, data gathered was reviewed with respondents to ensure factual consistency. 


\section{RESEARCH FINDINGS}

The findings clearly indicate insurance companies are integrating the Internet and Internet-related technologies into their business processes, and are moving towards increased reliance on the Internet to serve as an electronic commerce medium.

\section{Electronic Communication Effect}

The refers to the Internet's ability to communicate more information in the same amount of time and decrease the costs of communication (Malone, Yates and Benjamin 1987). After reviewing the interview data the findings can be grouped into the nature of communication, scope and structure, types and alternative means of communication.

\section{Nature of Communication}

The Internet's impact on organisational communication was found to vary according to organisational perspective. The primary finding in this area, as stated by one respondent, was, "...use of the Internet is definitely a revolution taking place within forward-thinking organisations, especially with the strategic development of Intranet and Internet technologies." The previous statement was supported by the following data:

- assuming proper management methods, respondents considered that the costs of industry communication will decrease dramatically as more information is distributed through the Internet (attributed to reductions in content production, distribution, postal delivery, and content maintenance costs)

- communication effectiveness will increase as information is customised and tailored to individual and organisational needs

- the Internet has the potential to service the insurance triad (consumer, agent and company) as an open communications network with platform independence

- the Internet allows for more timely, convenient, and current information to be communicated for customer consumption

However, with the change in the nature and medium of communication, other issues of concem emerged. Respondents were concerned about long term issues such as information structure and engagement, education processes, and servicing abilities. These dimensions of the Intemet remain superficially explored and were noted as needing further analysis to be fully understood. Another concern was the Internet's current passive nature in which information providers are given little control over information consumption. Currently the manner in which information is accessed and consumed is determined by Internet browsers. Thus, the value of communication structure was seen as becoming increasingly important.

\section{Communication Scope and Structure}

The Internet's national and international user base allows organisational information to be communicated to a broader audience and in greater depth. While the manner in which information is structured, integrated and tailored was identified as being very important, there was little agreement across respondents on the nature of these. For example, some respondents felt digitising hard copy brochures for Internet distribution was appropriate, while others felt it to be "shovel-ware" in which information overload and ineffectiveness were end results. In short, professional, readable web sites were seen as difficult to structure to provide organisational value, with the tendency for such sites to require large amounts of organisational resources from companies.

\section{Means of Communication}

The Internet's ability to facilitate an alternative means of communication with agents and consumers was found to be beneficial. For example, one respondent mentioned his company's plan to develop "...multimedia product information that can be downloaded for agency and consumer use." The Internet's multimedia capabilities provide carriers with an ability to deliver multifaceted and multidimensional information for consumption. The limits of the Internet were acknowledged (i.e., bandwidth, reliability, access, etc.) but the network's potential to advance and improve the current communication system was cause for optimism among respondents.

However, the Internet's ability to fully serve as a means of communication with consumers and agents and replace traditional methods was viewed with scepticism, especially with the current business value seen to be provided by independent agents. 


\section{Conclusion}

Overall, the "electronic communication effect" of the Internet was perceived as positive. Respondent data indicates organisational adoption of the Internet into business processes and strategic objectives. All respondents provided information as to how they plan to incorporate Internet communication into their businesses though the degree of involvement varied between simple web site advertisement and in-depth agentcompany interactivity. faith and confidence in the Internet's ability to fully serve as an electronic communications medium seemed to be limited at present due to technological and market barriers. The communication benefits noted lead to consideration of the Internet as a medium to supplement existing communication and distribution channels used by the companies to communicate with agents and consumers.

A numbs: of issues emerged during the interviews regarding the electronic communication effect which remainec inanswered and warrant further study, including:

- an adequate method to measure the value that an organisation receives from communications over the Internet was not provided and remains unclear

- the total reductions of organisational costs of Internet communication need to be compared against the additional costs for staff Internet training and support (especially related to production and maintenance of Internet communication)

- the degree of information engagement by consumers on the Internet remains to be an issue of speculation

\section{Electronic Brokerage Effect}

This section of the study attempted to explore the Internet's ability to act as an electronic market connecting many different buyers and suppliers, thus increasing the number of product alternatives that can be considered, increasing the quality of the alternative selected, and decreasing the cost of the entire product selection process (Malone, Yates and Benjamin 1987). The Internet's growth and development as an electronic market has led to the emergence of new target markets. Specifically, the "book-end effect" emerged as an important concept, which holds young, educated people and older, more established individuals participate in the Internet's growth, but a large number of individuals are in the middle of the two groups and remain "unconnected" to the Internet.

The electronic brokerage effects can be grouped into the search process, consumption process and market outcomes, and market structure.

\section{Search Process}

The Internet was seen as a means to facilitate the search process, especially as the insurance market evolves towards more educated and "technology savvy" individuals. Such an emerging market was specifically mentioned as a target for companies to address with new resources and business strategies on the Internet.

The Internet was seen as providing consumers with an easily accessed and potentially more efficient medium for insurance product education and selection. For example, Medical Savings Accounts (MSAs) are a new product that has emerged in the US health insurance market during the last few years. MSAs can be actively researched, analysed and selected with the Internet.

The Internet's ability to serve as an electronic broker was seen as a means to increase the level of consumer and agent knowledge of insurance products and servicing. The accessibility and convenience of insurance information on the Internet provides consumers with a means to "...look for what they really want to know." The emergence of push technology to provide insurance consumers with information they want to receive (an example given included Point Cast [www.pointcast.com] tailored to insurance). Additionally, the increase in the number of alternatives that can be considered was seen to improve insurance education and understanding, provide a means for comparison against captive agents, offer a means to fight for increased market share with better price and product offerings, and allow consumers to improve their ability to match their needs with an appropriate insurance product.

The need for filtering mechanisms to provide balance between information available and information needed at a one-to-one mass communication level emerged as a significant issue. Respondents noted the challenge the Internet poses to companies interested in not overwhelming consumers with technical and non-technical insurance information, and yet differentiating themselves from the masses of potential information that exists and increases daily. An improved information delivery and filtration mechanism to facilitate buyer and seller matching and consumer understanding of insurance products was seen as important to promoting further Internet market development, as one respondent said, "we need to go beyond search engines and directories to form customised technology that offers a unique point of view for customers." 


\section{Consumption Process}

An area of debate was how insurance products and services on the Internet would be consumed and the possible market outcomes. Two possible consumption processes emerged during the study:

- insurance products and services would be located and researched on the Intemet, after considering possible altemative insurance products, additional information and assistance would be sought through a retail outlet or personal contact, and the transaction would be continued "off-line"

- insurance products and services would be located and researched on the Internet, after considering possible alternative insurance products, additional information or guidance would be sought online, and the insurance transaction could be completed either on the Internet or "off-line"

\section{Market Outcomes}

From these two possible consumption processes, two possible market outcomes were identified. One market outcome was seen to lead to disintermediation supported by Internet development and the emergence of on-line intelligent software agents. The other market outcome was seen to result in a large number of people relying on personal interaction through traditional market mechanisms. It should be noted that these outcomes represent endpoints in a market outcome spectrum in which different market strategies could emerge. Disintermediation is discussed in more detail later in the paper.

Respondents generally cited the following market outcomes for insurance industry members participating on the Internet:

- reduction in insurance market barriers resulting in increased electronic marketplace competition

- customisation of products and services

Among solutions that have emerged, the on-line insurance mall was seen as the least promising. The need to understand consumer demographics and needs, and market on-line insurance products accordingly was seen as a promising objective. Examples of such marketing techniques were the bundling of insurance information with affiliated web sites and news groups. Additionally, the potential for other financial service firms to enter into the Internet insurance marketplace was seen as an emerging reality. While respondents were aware of the need to differentiate their organisations from other organisations participating on the Internet, the approach for doing so remained firm specific.

\section{Conclusion}

The Internet's ability to connect many different buyers and sellers of insurance was clearly recognised by respondents. The fundamental business concern that emerged regarding commerce on the Internet was how to separate one's organisation and product offerings on the Internet from rival organisations on the Internet. The filtering mechanism respondents mentioned as necessary for effective and efficient matching of consumers with products have not yet matured, though recent developments in agent-mediated electronic commerce suggest progress is being made in this area. The respondents acknowledged the Internet's ability to serve as a local, national and international interconnected marketplace matching buyers and suppliers. However, the business value and implications of participating in electronic commerce over the Internet remained organisational specific and tied to strategic speculation and inference.

\section{Electronic Integration Effect}

This section of the interview guide attempted to explore the Internet's ability, not just to speed communication, but to also change the business processes that create and use information (Malone, Yates and Benjamin 1987). By asking respondents for their opinions as to how the Internet can change their business processes, insight was gained into how use of the Internet as an electronic market changes the role information technology and information in their firms. The findings from this section were grouped into business process impacts, customer support, organisational speed, distribution and information use.

\section{Business Processes}

The development of Internet and Intranet technologies was seen as a tool for organisations to change their business processes to respond to new and emerging market needs. However, the theme that "...companies and agents are like dinosaurs, a lot of them aren't up to speed and have plenty of obstacles in front of them," emerged as a common view among respondents. 
The Internet is allowing many of the participating firms to rethink the best manner for them to organise and conduct business, especially those functions which are supported by information technology. Such thinking led respondents to provide the following views regarding Internet technologies:

- the incorporation of data warehousing, databases, and decision support systems with Internet technologies increases organisational ability to improve business practices through work-flow reengineering and building new business applications.

- as a technology infrastructure for business processes, the Internet and related technologies are more affordable and flexible (i.e., open standards, browser technology, accessibility, etc.).

- the Internet facilitates the crossing of organisational boundaries and the seamless integration of vendor and agent operations.

- potential business processes for change include enabling streamlining of functions, increased speed to market, and on-line claim status checking and coverage changing abilities.

\section{Customer Support}

The Internet's ability to serve as a tool for companies to build customer support and service emerged as an immediate target for organisational resources. During the interviews it became clear that interconnected communications links between agents, companies and consumers could benefit carriers immensely. The targeted benefits varied between respondents, but some common areas of possible interest for improvement were:

- the Internet to serve as a tool to support and enable agents and consumers (Example: obtaining quotes faster, more in-depth marketing information,)

- increasing consumer comfort with on-line insurance servicing

- increased consumer servicing and communication (especially with claim reporting, billing status, claim status, etc.)

- improving agent-company relationships

- building carrier reputation and brand recognition on the Internet

\section{Organisational Responsiveness}

An issue that emerged during the interviews was organisational speed in meeting consumer needs and responding to market changes. The prospect of having consumers and agents interacting with organisational members instantaneously through e-mail rather than the traditional postal system has begun to encourage the organisations participating in the study to rethink how, where and when consumers interact with them. Also, the ability to create a customer and agency feedback mechanism through the Internet to improve organisational learning was seen as an important area for development.

\section{Distribution}

The manner through which carrier information, products and services are distributed was provided as an example of how the Internet is changing distribution. Respondents saw the Internet's potential to integrate publications, coverages, agents, purchasing information, relevant news, and other information into a medium of value added distribution, as having a profound impact on their businesses. However, a distinction should be made between those who had strategic, longer term outlooks on the business impacts of the Internet and those who had more operational, short term oriented views. The immediate short term outlook on the Internet's impact on distribution was seen as serving as an alternative or additional mechanism for agency and company use.

\section{Conclusion}

By focusing on how organisations anticipate electronic integration of the Internet into their business processes and strategic objectives, insights emerge about how insurance carriers see business processes, customer support, organisational speed, distribution and information use are being impacted by the Internet. In summary, it became evident from the interviews that the Internet enables not only increased speed of communication, but also can serve to provide a platform for organisations to rethink and re-engineer business processes.

\section{Effects of and upon Insurance Product Characteristics}

This section of the study considered the suitability of insurance products for transaction over the Internet. To identify respondents views on the suitability of insurance products for an electronic market environment, we examined product characteristics and non-contractible investments. 


\section{Insurance Product Characteristics}

In an attempt to understand whether insurance products and services distributed through the Internet would be viewed as a commodity or differentiated product, respondents were asked for their views on the nature of their products and services. From the insurer and agent standpoint, it was discovered to be advantageous to have insurance products seen as differentiated products. However, the advent of the Intemet as a communications and information rich medium changes how insurance is perceived in an electronic marketplace environment.

Personal lines insurance was seen as being closer to a commodity product, with commercial lines insurance being more differentiated. However, it was also found that a spectrum exists along a continuum between personal lines (for example personal auto insurance) as a commodity product and commercial lines (for example commercial coverage against environmental liability) as a differentiated product, with different market segments served by different product and service combinations. Additionally, price and quality interact with the different product and service combinations to increase product differentiation. However, the essence of insurance content in different products remains similar due to the manner in which insurance is regulated, thereby restricting the ability of companies to truly differentiate their products from competitors.

Respondents recognised the potential for opportunistic companies to develop products and services tailored for Intemet distribution as a possibility. Such an Internet tailored product would be developed to be clear, simple, and concise to maximise consumer understanding. However, as assistance at the point of sale is improved through Internet communications, the long term impact of product characteristics (whether a commodity or differentiated product) was seen to be minimised. Also, the development of on-line comparative quoting mechanisms and improved consumer education on insurance products was seen to increase the difficulty for insurers to differentiate their products. Finally, the amount of consultation and expertise a consumer requires to purchase insurance also affects how different product and service offerings would be differentiated from competitors.

In addition to the whether a product is a commodity or differentiated, other product characteristics influence how the product is distributed in an electronic marketplace (Malone, Yates and Benjamin 1987). The emerging fluidity between traditionally separate financial service organisations and their products have led to an increase in product bundling. With banking, personal finance, and insurance products becoming increasingly packaged together, combined with increased Internet usage by consumers, consumer market preferences were found to be changing. The ability to connect and bundle related products on the Internet through hyperlinks and web site integration creates an environment in which product marketing and fulfilment could be welded together into one interactive session for the consumer.

One primary characteristic of insurance products however hinders the ability to fully integrate insurance with other products on the Internet: product complexity. During the study it was found that insurance product complexity influences consumer education, customer communication, and the migration of insurance to an online environment. Consumer education is required in order for a potential customer to understand their actual coverage needs, and to assist an insurer in adequately matching a product with the customer's coverage needs. With different market segments having different product needs, the ability for consumers to use the Internet to purchase insurance requires a customer to adequately understand various product offerings and select the appropriate product. To improve the product selection and attainment processes on the Internet, customer communication was seen as vital. Providing a means for effective communication with customers on the Internet is essential for carriers and agents to assist customers in understanding and reviewing their product offerings.

The interviews also revealed that the nature of the on-line environment supporting complex transactions affects the suitability of different insurance products supplied through an electronic distribution channel such as the Internet. To many consumers, the combination of insurance and Internet complexity is potentially overwhelming. Thus, in addition to simplifying the insurance products offered, the Internet "experience" provided by insurance sites needs to be structured to maximise effectiveness. To prevent or at least minimise consumer confusion, the assistance of insurance agents and consumer software to support on-line insurance transaction applications was seen as a requirement. With the assistance of an agent and/or available software applications, consumers could be guided through the process of researching, buying, or adjusting their insurance coverage. An example of a consumer assistance software application could be a down-loadable program to facilitate independent analysis, financial modelling, and/or comparative rating. Such applications, combined with hyperlinked, multimedia environments, were found to support companies and their agents' abilities to facilitate electronic insurance commerce.

The successful migration of insurance onto the Internet was found to have occurred when "...simple and complex insurance transactions were efficiently completed and professional agent consulting moved away from transaction processing towards more value-adding situations of meaningful customer contact and support." The point of customer contact was seen as the most crucial point for effective, efficient and quality service. The ability to use the Internet as a tool to add as much value as possible to the point of customer contact represented a valuable opportunity. 


\section{Non-Contractible Investments}

The concept that organisations and individuals may limit the total number of suppliers considered in order to maximise non-contractible investments, such as quality, responsiveness, trust, information sharing and innovation (Bakos and Brynjolfsson 1993), was found to be relevant for Internet insurance transactions. Fundamentally, it became evident that the value of non-contractible investments increases as other differentiating characteristics are eliminated. Efforts by carriers to add more value for agents and consumers engaging in electronic commerce were seen as valuable, directly increasing the importance of "soft issues."

The emergence of instantaneous transactions and communications with agents and consumers increases the role professionalism, quality and customer service have on the Internet. It was seen that the purchase of insurance, as a complex transaction, requires the process to be supplemented with professionalism, increased emphasis on credibility and protection, ease of doing business, personalised service, process simplification and streamlining, personal interaction, responsiveness, innovation and other value adding mechanisms. The challenge presented is how to provide and highlight such "soft issues" on an information and communication network such as the Internet.

Although the fundamental business and underwriting processes do not change with increased Internet usage, the delivery and service of those processes are radically altered by the Internet. Implied trust and credibility are provided through a well recognised and accepted brand name which assists in legitimising new business processes and servicing channels. However, fraud awareness, customer privacy, and information protection were seen to increase in importance. Thus, the integration of the Internet to support traditional business processes in a new distribution channel requires not only adherence to organisational values and objectives, but also a consistency with the organisation's Internet business values and strategic objectives. Such a duality of organisational existence between its marketplace and its marketspace was seen as a complex issue that will continue to emerge, and require the creation of new, more flexible business models.

\section{Conclusion}

As previously mentioned, this section of the interview guide focused on the suitability and nature of insurance products to be applied to the context of the Internet. Different lines of products were seen to be more suitable for electronic commerce on the Internet, with the characteristics of those products influencing how they are marketed, distributed and serviced. With the inability to readily distinguish one carrier's product from another, the importance of other factors, such as non-contractible investments, was seen to increase.

\section{Evolving Market Structure and Process}

This section of the interview guide focused on how the Internet may impact market relationships in the independent insurance agency system. Issues such as how members in the industry triad will communicate over the Internet, possible transaction paths of commerce, and consumer switching costs were explored.

In an attempt to understand what type of electronic market characteristics would emerge with the entrance of the Independent Insurance Agency System onto the Internet, the role of supplier relationships, buyer demographics, transaction pathways, network switching costs, price and product information, price competition, alliances, and regulation were explored.

\section{Supplier Relationships}

The respondents viewed the Internet as relationship technology where agents and insurance companies can embrace the technology to work with customers to provide products and services according to their needs and preferences. The proprietary issues involved in agent-company relationships encourage closer alignment between the two, which encourages co-operation in introducing and utilising new information technology solutions over the Internet. The Internet was seen as providing easier connectivity and a tool to supplement existing relationships.

\section{Buyer demographics}

Another area of importance was recognised to be emerging markets of younger, more technologically exposed individuals, and the need to monitor and respond to their buying preferences and practices. If such an emerging market were to increase in size and attractiveness, the nature of market relationships could easily change. 


\section{Transaction Pathways}

The question of whether current transaction pathways will remain the same or change as the Internet is used for servicing insurance consumers remains to be seen. While respondents believed market preferences determine industry structure, they also suggested that the flow of information between entities will emerge as an important influence on industry structure in the future. Such a concept illustrates how the independent insurance agency system is vulnerable to an electronic marketplace such as the Internet where information flows freely and is accessed at the convenience of the user.

The interviews also uncovered that the flow of information between consumers, agents and companies on the Internet is not one-dimensional or biased towards one entity, rather the manner through which the information is used is the distinguishing feature of information based commerce. Thus, the Internet serves as an information tool that will supplement buyer preferences, with those preferences determining the path followed in a given transaction. For example, one respondent gave the example of an agency web site seamlessly integrated with his company in which a browser located a local independent agent's web site and used the agent's web site as the structure for securing insurance from the Internet. Such an example highlights the possibility that the physical distinction between agency and company becomes blurred in the virtual world, with consumer preferences determining transaction patterns.

\section{Buyer Loyalty and Switching}

The increased ability and convenience of consumers to search for insurance products were seen as factors that may influence customer renewals. It was found that numerous external factors influence whether consumers renew their policies with a given company. However, it was noted that an increased ability for consumers to search and switch was not beneficial to carriers. An increased tendency to search was seen as leading towards product price having a larger role in product selection, and created a contradiction between those who saw the Internet as facilitating and building closer relationships between companies/agencies and their consumers, and those who saw the Internet as decreasing relationships. Negative impacts of switching included increased organisational operating costs to support products and customer servicing, and potential threats to coverage renewals.

\section{Product and Price Information Availability}

When respondents were asked how price and product information on the Internet would impact insurance distribution, the following factors where seen to interact with how product and price information are utilised on the Internet:

- Education- consumer education through the Internet serves an important role in helping buyers understand insurance products and rating mechanisms, but also increases their product/service awareness and expectations

- Needs Assessment- the population of Internet users mirrors the traditional insurance consumer population in which different buying segments have different buying preferences, including those who are price oriented, relationship oriented, and protection coverage oriented

- Market Maker- the ability of and incentive for an organisation to create an environment of on-line, comparative insurance shopping has not been fully realised at present. Although different organisations were noted as attempting to build an on-line insurance marketplace (for example InsWeb <www.insweb.com>) the current initiatives were seen as limited and with minimal benefits

The ability of consumers to conduct rate comparisons was seen to be increased as a result of the Internet. At present, the time and process to conduct rate comparisons are absorbed by independent agents or consumers. However the findings indicate the ability of a market maker to create a favourable environment on the Internet for comparison shopping would be beneficial. In such an environment, product and price information would be available for consumers to assist in assessing product needs.

\section{Price Competition}

The effect the Internet has on price competition between insurers was seen to be limited to the business strategy the organisations have developed. Depending on whether a carrier's competitive strategy is based on cost, service, and/or quality directly influences the Internet's impact on price sensitivity. Additionally, the price mechanisms are not in place to provide quick responses to customer inquires (most Internet quotes are delivered though e-mail or the telephone), and the organisation and system structures have not been developed (the costs were seen as too high due to different rating mechanisms and state regulation variables). Although such impediments to price competition exist, the long term perspective suggested that price would have an increased 
role in product selection, and that margins would decrease to meet increased customer demands on price, quality and service. One proposed effect of price competition on the industry would be increased instability as premiums were lost and carrier adherence to strict underwriting guidelines was relaxed.

\section{Disintermediation}

The Internet's impact on market intermediation and the role of agents in insurance distribution was seen by respondents as a significant business issue. As the Internet's ability to fully serve as an electronic marketplace evolves, some respondents believed that market competition from other financial and non-financial organisations would increase, that cost reductions would be more aggressively sought, and that the market role of the independent insurance agent would change.

Evidence of the four possible market intermediation outcomes (see Figure 3) proposed by Sarkar, Butler and Steinfield (1995) is visible within the insurance industry. A direct market supported by an electronic marketplace has emerged with auto insurance. It is believed direct marketing will have a larger role with personal insurance lines in the future. The growth of direct markets through the Internet is considered to threaten current intermediary structures. However, agency use of the Internet to supplement their business practices (outcome IV) was seen as viable due to the emergence of business plans and strategies by insurance agents to create market niches and continually add value to the insurance transaction process. This is especially prevalent in commercial lines insurance.

An interesting area to observe in the future is whether cybermediaries will emerge on the Internet to serve the interests of the insurance buying public. Although industry trade press and study respondents alluded to the development of cybermediaries (for example the market maker InsWeb <www.insweb.com $>$ ) the competitive impact and influence of their activities to date were seen as minimal, and too early to anticipate future impact.

With current disintermediation targeted towards personal insurance lines, and possibly small commercial lines, the potential for adverse selection in favour of organisations aggressively utilising the Internet was found to increase. Some carriers and agents could potentially limit their relationships to organisations using the Internet, and build relationships from a common commitment towards integrating the Internet into their business processes. While some respondents believed the industry as a whole could slow insurance migration on to the Internet, others believed service providers from different sectors and industries could enter the market and compete using Internet technologies, negating any prolonged industry hesitation. Thus, rather than impede the industry's growth on the Internet, it was seen as being more viable to work with agency system members (i.e., agents and vendors) to develop the technology and understanding within the window of learning that now exists.

Another aspect of disintermediation was the manner in which non-Internet related issues influenced the use of market intermediaries. It was previously noted that different market segments have different buying attitudes and preferences towards product quality, price, service, and other product attributes. Overall, respondents noted that disintermediation was already occurring in certain markets without the Internet through utilisation of directing marketing and toll-free telephone channels. The Internet was seen as a new alternative to traditional direct marketing methods.

The findings of the study suggest differences between traditional direct marketing opportunities and those emerging on the Internet. The emerging opportunities represent a new approach to deliver insurance services to consumers. Thus, disintermediation has become an increasingly viable possibility due to the Internet, but the Internet itself will not be the sole force pushing disintermediation. Therefore, agents need to recognise changes in market demographics and consumer buying preferences to continually understand how they can provide added-value services on the Internet.

Overall, the independent agency system's future was not seen as dire, rather it was suggested the system would merely change and adapt to new market demands. The analogy of the agency system to a triad in which insured, agents, and carriers represented the three points emerged as an interesting concept. With the emergence of the Internet, information flow in the triad is multilateral and flows in different directions determined by information requirements. Triad members exist to complete the insurance transaction, with their position in the triad determined by the market value provided and their individual business objectives. A networked environment of the triad was found to facilitate information exchange and seamless integration.

\section{Mergers and Strategic Alliances}

The kiosk analogy to ATM networks that emerged during the study also serves the purpose of illustrating opportunities for mergers, strategic partnerships, and new market entrants to offer insurance products on the Internet. Some respondents recognised the ability for a large retail organisation (such as a bank) with an established Internet presence to include insurance products in its on-line product portfolio. With the Internet it would not matter whether the insurance products originated within a business unit or from a strategic partner due to the Internet's ability to seamlessly integrate products and services using hyperlinks and multimedia. Again the concept of a market maker emerged, but was tailored to joint efforts of multiple organisations to create the basis 
for an on-line market maker. Such an initiative was mentioned to potentially include a technology provider, product supplier(s), and unbiased third party evaluators.

\section{State Insurance Regulation}

Insurance regulation was determined to have a profound impact on how the insurance industry participates on the Internet. Although the United States Federal Government has endorsed national commerce on the Internet, insurance remains under the legislative control of state legislatures and the regulatory control of state insurance commissioners, resulting in laws and regulations differing from state to state. Thus, a potential area for conflict of interest has emerged in which although insurance is individually regulated by each state, the Internet serves a national and international consumer market. While the legislative and regulatory issues regarding insurance and the Internet are not in the scope of this study, it is essential to note the conflict of interests, and the task facing insurance regulators and the insurance industry to resolve interstate and international electronic commerce issues.

\section{Conclusion}

The interviews revealed how market relationships, transaction paths and switching ability would be affected by the Internet. The Internet was widely seen to be organisationally and market neutral, with market forces dictating the structure of the independent insurance agency system on the Internet. Some important business issues emerged regarding how electronic market characteristics influence the entrance of the independent insurance agency system onto the Internet. With the wide availability of information resources and the emerging availability of price comparison, the respondents provided insight into strategic and operational issues that need to be addressed. While the time frame for carriers and agents to fully integrate the Internet and related technologies is uncertain, the strategic and business issues need further consideration and analysis to help facilitate the system's transition towards electronic commerce.

\section{Economics of Market Participation}

\section{Benefits of Participation}

The immediate benefits for agencies of participating on the Internet were found to be mostly based on subjective rather than objective criteria. However, insurance carriers indicated they are attempting to build the economic justification for agency participation on the Internet. The economic justification for agents and companies to participate on the Internet focused on promoting the following benefits:

- elimination of software distribution

- reduced transaction processing costs

- improved information distribution

- decreased overall information technology costs

- improved quality of the investment by associating it to functionality

- value from e-mail communication

- audit tracking

- brand name and product recognition

- improved consumer understanding and education

- increased advertising

- niche attractions through specific fact sheets and customised information

- improved service beyond contract requirements

General optimism surrounded carrier motivations for Internet participation, but a strategic theme emerged in which the Internet's ability to eventually become integrated into the industry's business processes and therefore become a strategic necessity was noted. The Internet's ability to provide a flexible business platform for companies and agents to interact and serve customers was a primary reason for integrating the Internet into business processes. Also, as the Internet's integration into fundamental insurance business practices continues, the potential business value provided to carriers by the Internet was seen to increase.

Without active agent participation on the Intemet technologically facilitated adverse selection was seen as a distinct possibility. In such a situation, those intermediaries who were not participating in electronic commerce would be automatically excluded from future Intemet developments and advancements. Additionally, agents were seen as preferred partners in Internet facilitated insurance commerce, but it became clear that if consumer demand for direct interaction with companies increases or the benefits of direct interaction change, agents will not be able to block carriers from interacting with consumers on the Internet. The potential to alienate agents by carrier activity on the Internet was seen, but prevention of such alienation was directly targeted through 
continued reliance on the present agency distribution forces. However, carriers continued to find value in Internet exploration and participation, especially with insurance marketing and product information.

Additionally, advances in Internet technologies were seen as facilitating widespread adoption of Internet usage into core business practices, and further promoting the eventual adoption of Internet participation as a strategic necessity.

\section{Network Externalities}

At present, the benefits carriers derive from the Internet were not directly linked to the number of participants on the Internet. The carriers benefit from the Internet indirectly by communicating with Internet users about their product and service offerings. However, carriers are trying to assess long term benefits of electronic commerce and are exploring the appropriate business processes for re-engineering. Overall benefit of participation was attributed to capitalising on new consumer demands by using technology solutions in delivering new business visions.

\section{Investment and Operational Costs}

The initial costs and investments required for participation on the Internet were justified based on carrier strategic outlook for the future. The strategic outlook for the carriers incorporated a three to four year timeframe in which the means of exchange and communication methods change to align with the "digital economy". In such an environment, it was considered that adverse selection could occur in which high performance agents participating on the Internet with strategic information technology plans would increasingly benefit at the expense of low performance, non-Internet-participating agencies.

\section{Network Switching Costs}

Organisational investments in Internet technologies were seen as sound investments due to the limited switching costs faced by Internet participants. The Internet's design and infrastructure allow for flexibility in information technology investments (for example client server technologies, open standards, and platform independence) provide for flexible investments to address different business functions. Organisational benefits from Internet investment included open network standards allowing for increased agency-carrier interfacing and information exchange, as opposed to proprietary networks that can be cost intensive and investment specific, with reduced business flexibility.

\section{Agency Capital Investment}

The initial capital investments for independent agents were seen as minimal. With current Internet service provider costs relatively low, and the ability to incorporate Internet services into agency management systems, it was seen to be in an agent's best interest to invest in Internet participation. In addition to having companies and agents working together to build the technological ability to use the Internet to serve customers, the initial capital investment was seen to be near zero, especially due to agency abilities to build on information technology systems already in place. In such an environment the main costs were seen to be participant education and awareness of the Internet and its potential uses.

To quantify the investment costs it was deemed important to look at return on investment as the ability to interact with customers, and to improve customer and carrier relationships. The tendency for agents to focus solely on sales should not be the sole objective; lead generation was suggested as a potential longer term objective as the technology evolves.

A cost spectrum developed in which the cost of participation directly relates to the business value derived from the Internet. For example, as the interactivity and business value increase in a web site more investment and capital outlay are required. The lower the interactivity and business value of a web site, the lower the cost. For example, for a web site to adequately support sales and customer servicing requires more investment than a simple site with advertising and product information. Without specific business methodologies or plans to manage the relationship between increased cost and increased business value, the fundamental objective was seen to view investment in the Internet as an investment in future business productivity and processes. Finally, it was discovered to be essential to consider business and strategic issues before developing an Internet presence. Such consideration was seen to improve the likelihood of organisations avoiding wasted effort and resources, and maximising the benefits. 


\section{Prisoner's Dilemma}

The concept of the prisoner's dilemma in electronic marketplaces (sellers as a group do not benefit from an electronic market system, but as individuals the revenues that can be generated from such a system can benefit them and outweigh the losses) advanced by Bakos (1991) was adapted to this study and used to understand insurance carrier motivations and concerns for Internet participation. First mover benefits were seen to be organisational specific due to different carrier strategic and business objectives for Internet development. Latemover benefits were attributed more towards functional benefits derived directly from Intemet capabilities (for example using e-mail as an alternative communication means).

Although optimism and enthusiasm were associated with Internet business development, concerns regarding how the industry and distribution systems would adapt, and how market competition could change remained a primary concem. The ability for financial and other non-financial institutions to leverage their organisational network capabilities, resources, and customer bases to enter the insurance market consistently also emerged as a concern. Disadvantages of widespread Internet adoption were seen to include rate reductions due to increased price and market competition, increased commonality of value added services through industry standard elevation, increased market threats from merged consumer processes and product bundling, and a reduction in total market participants.

An interesting concern discovered was whether a global interconnected electronic market such as the Internet would lead to a more globally competitive, digital insurance marketplace. From the study's findings it became evident that state regulation and oversight of insurance was seen as a substantial factor in keeping insurance localised to individual regions and states, rather than leading to increased national and international free market competition over the Internet.

\section{Conclusion}

With the wide availability of information resources and the emerging availability of price comparison, the respondents provided insight into strategic and operational issues that need to be addressed in relation to electronic market participation. In addition to understanding and justifying the benefits of participation, the role Internet economics have in facilitating its adoption throughout the agency system was exposed to include switching costs, capital investments, and network externalities. While the time frame for carriers and agents to fully integrate the Internet and related technologies is uncertain, the strategic and business issues need further consideration and analysis to help facilitate the industry's transition toward electronic commerce.

\section{OVERALL CONCLUSIONS}

The research objectives of this study were established to undertake exploratory study on how the Internet, as an electronic market, is changing the American Independent Insurance Agency System. The organisations interviewed for the study provided perspectives from the insurance producer's point of view. The intent of pursuing such a perspective in this study was to help independent insurance agents understand relevant market forces and insurance carrier motivations supporting Internet participation, and to improve overall industry understanding of how electronic commerce on the Internet impacts organisational and market stnucture.

As the findings indicate, a number of issues were explored through the interview process to provide in-depth, contextual understanding of the issues involved with Internet facilitated electronic commerce related to insurance. During the exploration process a number of unexpected issues were also uncovered and discussed. This combination of established and unexpected research topics for study and discussion contributes in creating practical value for those interested in understanding current complexities and concerns regarding the growth of insurance-based electronic commerce on the Internet. Thus, the research significance of this paper is its approach to presenting and discussing electronic commerce at a general, conceptual level, the creation of a strategic framework for assessing electronic commerce by extracting core constructs and propositions from such a presentation, and applying the framework to a specific industry.

From the data collected during the interviews it can be concluded that the Internet is beginning to have a profound impact on the American Independent Agency System. The common theme throughout the study was the existence of organisational awareness of a growing Internet role in the insurance industry, and strategic planning and operations for building the reliance on and use of the medium. Other conclusions that can be drawn from the study include the Intemet's ability to offer organisations new methods and practices for conducting business, including:

- enabling more information to be communicated in the same amount of time and decrease the costs of communication

- providing a medium to connect many different buyers and sellers, and facilitate product offering and buyer need matching 
- allowing organisations to change business processes and information usage methods

- changing traditional market relationships to favour greater efficiency and productivity with increased market value

- encouraging sellers to differentiate their product to prevent commoditisation

- increasing the possibility of disintermediation, with an overall emphasis on the value of different possible electronic market intermediary roles (For more information see Figure 4.3)

It is important to again note the qualitative nature of this study. To successfully achieve the research objectives of this paper qualitative research was selected, primarily due to the early stage of theory building in the chosen research topic area. Possible future research includes the development of a larger study sample with a less qualitative structure to provide a more in-depth, less narrow, empirically grounded research study. Due to the lack of established academic and insurance industry theories pertaining to the Internet's ability to facilitate insurance related electronic commerce in a market environment at present, such an approach was not taken. Study weaknesses were minimised as much as possible, to maximise the practical and research significance of the study. Additional empirical and conceptual research needs to be undertaken to explore and test the issues that emerged during this study. Finally, as Internet technologies develop and insurance industry adoption of electronic commerce increases, additional research should be conducted to evaluate the long term strategic outlook for the American Independent Agency System.

\section{REFERENCES}

Bailey, Joseph P. and J. Yannis Bakos (1997): “An Exploratory Study of the Emerging Role of Electronic Intermediaries", International Journal of Electronic Commerce, Vol 1, No 3, pp.

Bakos, J.Y. (1991): "Information Links and Electronic Marketplaces: The Role of Interogranizational Information Systems in Vertical Markets", Journal of Management Information Systems, X, X, pp.

Bakos, J.Y. (1991b): “A Strategic Analysis of Electronic Marketplaces”, MIS Quarterly, September, X, X, 295-310.

Bakos, J.Y. (1997): “Reducing Buyer Search Costs: Implications for Electronic Marketplaces", Management Science, December, $X, X, \mathrm{pp}$.

Bakos, J.Y. and Brynjolfsson, E. (1993): "From Vendors To Partners: Information Technology and Incomplete Contracts in Buyer-Supplier Relationships", Journal of Organisational Computing, X, X, 301-328.

Banham, Russ (1997): "Cyber-Agents", Independent Agent Magazine, February, 16-21.

Barrett, S. and Konsynski, B. (1982): "Inter-Organisation Information Sharing Systems", MIS Quarterly, X, X, 93-105.

Benjamin, R. and Wigand R. (1995): "Electronic Commerce: Effects on Electronic Markets", Journal of Computer Mediated-Communication, 3, 1-14.

Benjamin, R. and Wigand R. (1995b): "Electronic Markets and Virtual Value Chains on the Information Superhighway", Sloan Management Review, Winter, 62-72.

Block, Michael, Yves Pigneur and Arie Segev (1996): "On the Road of Electronic Commerce-- a Business Value Framework, Gaining Competitive Advantage and Some Research Issues," Working Paper: Fisher Center for Information Technology and Management, University of California, Berkeley, [URL:http://130.223.171.154/yp/pub/road_EC/]

Brandel, Mary (1996): "Is the World Ready for Web Quotes", Computerworld Electronic Commerce Journal, April 29, 12.

Cash, James I., Jr. (1996): “The Point of the Exercise - The IT Treadmill May Seem Like More Trouble Than It's Worth, But You'll Feel the Difference as the Corporation Firms Up", Information Week, November 25, 128.

Champy, Jim (1997): “How Should You 'Push' Your Pitch to Consumers?", Computerworld, May 26, 72.

Clemons, E.K., Reddi, S.P., and Row, M. (1993): "The Impact of Information Technology on the Organisation of Economic Activity: The 'Move to the Middle' Hypothesis", Journal of Management Information Systems, Fall, 9-35.

Clemons, E.K., and Michael Row (1993): "Limits to Interfirm Coordination Through Information Technology: Results from a Field Study...”, Journal of Management Information Systems, June 1, 73.

Coase, R. H. (1937) "The Nature of the Firm" in Williamson, O. E. and Sidney G. Winter (YY) The Nature of the Firm: Origins, Evolution, and Development, Oxford University Press, New York.

Cole, Barb (1997): "Insurers Pay Premium for Secure E-Commerce", Computerworld, March 17, 4

Cortese, Amy (1997): “A Census in Cyberspace", Business Week, May 5, 85.

Eisenhardt, K.M. (1989): "Building Theories from Case Study Research", Academy of Management Review, $14,4,534-550$. 
England, Frederick J., Jr. (1993): "The Eagle Has Landed", in Ronald W. Vinson and Jack Payan (Editors), Soaring With Eagles: the Rise of Independent Insurance Agents in America, Independent Insurance Agents of America, Virginia.

Gray, Matthew (1996): Internet Growth Summary, Massachusetts Institute of Technology [URL:http://www.mit.edu/people/mkgray/].

Grover, V. (1993): “An Empirically Derived Model for the Adoption of Customer-Based Interorganizational Systems", Decision Sciences, May-June 1993, 603-640.

Gupta, Sunil (1995): "HERMES: A Research Project on the Commercial Uses of the World Wide Web," University of Michigan Working Paper, [URL:http://www.umich.edw/ sgupta/hermes/]

Gurbaxani, V. and Whang, S. (1991): "The Impact of Information Systems on Organisations and Markets", Communications of the ACM, January, XX, XX, 59-73.

Halper, Mark (1997): "Meet the Middlemen", Computerworld Emmerce, April 28, 10.

Hess, C.M. and Kemerer, C.F. (1994): "Computerized Loan Origination Systems: An Industry Case Study of the Electronic Markets Hypothesis", MIS Quarterly, September, X, X, pp.

Higgins, Kelly Jackson (1996): "Are We There Yet? - Not Really. Most are stuck on the slow road when it comes to EC. Three industries explain why", Communications Week, November 4, 61 .

Hines, Peter (1993): "Integrated Materials Management: The Value Chain Redefined", The International Journal of Logistics Management, 4, 1, pp.

Hoffman, Donna L., Thomas P. Novak and Patrali Chatterjee (1995): "Commercial Scenarios for the Web: Opportunities and Challenges", Journal of Computer Mediated-Communication, 3, 1-21. [URL:http://jcmc.huji.ac.il]

Jenkins John (1997): "Doing Business Electronically", Electronic Commerce Association: Business on the Internet Interest Section Internet Briefings, 3. [URL:http://www.eca.org.uk]

Kambil, Ajit (1995): "Electronic Commerce: Implications of the Internet for Business Practice and Strategy", Business Economics, October 1, 22(7), pp.

Kaplan, B and J.A. Maxwell (1994): "Qualitative Research Methods for Evaluating Computer Information Systems", in J.G. Andersen, C.E. Aydin and S.J. Jay (Editors), Evaluating Health Care Information Systems: Methods and Applications, Sage Publications, Thousand Oaks.

Kristula, Dave (1997): "The History of the Internet", A Section of Web Site Workstation [URL:http://www.davesite.com/webstation/net-history/]

Kroll, Ed and Ellen Hoffman (1993): "FYI on What is the Internet?", Network Working Group Request for Comments, 1462, FYI:20 [URL:gopher://ds1.internic.net/00/fyi/fyi20.txt]

Leiner, Barry M., Vinton G. Cerf, David D. Clark, Roberth E. Kahn, Leonard Kleinrock, Daniel C. Lynch, Jon Postel, Larry G. Roberts and Stephen Wolff (1997): A Brief History of the Internet, Version 3.1, Last revised February 20 [URL:http://www.isoc.org/intemet-history]

Malone, T., Yates, J., and Benjamin, R. (1987): "Electronic Markets and Electronic Hierarchies", Communications of the ACM, June, X, X, 484-497.

Mason, David and Mary J. Turner (1996): "Timing is Everything - Getting Into EC at the Right Cycle is Essential", Communications Week, September 2, S03.

Mehr, Rober I. and Emerson Cammack (1980): Principles of Insurance, 7th Edition, Homewood, Richard D. Irwin, Inc., Illinois.

Miller, Thomas E. and Peter C. Clemente (1997): "The 1997 American Internet User Survey, Realities Beyond the Hype", FIND/SVP, Emerging Technologies Research Group, May 6 [URL:http://etrg.findsvp.com/].

Myers, Michael D. (1996) "Qualitative Research in Information Systems," MISQ Discovery, X, X. URL:http://www.auckland.ac.nz/msis/isworld/]

Neville, John F. (1980): No Violations of Policy, Rough Notes Company, Inc., U.S.A.

Nouwens, John and Harry Bouwman (1995): "Living Apart Together in Electronic Commerce: The Use of Information and Communication Technology to Create Network Organisations", Journal of Computer Mediated-Communication, 3, 1-25. [URL:http://jcmc.huji.ac.il]

Payan, Jack (1993): "Gathering of Eagles", in Ronald W. Vinson and Jack Payan (Editors), Soaring With Eagles: the Rise of Independent Insurance Agents in America, Independent Insurance Agents of America, Virginia.

Porter, Michael E. (1985): Competitive Advantage: Creating and Sustaining Superior Performance, Free Press, New York.

Porter, Michael E. (1979): "How Competitive Forces Shape Strategy", Harvard Business Review, MarchApril, $137-45$.

Rayport, J. and Sviokla, J. (1995): "Exploiting the Virtual Value Chain", Harvard Business Review, November-December, $75-85$. 
Sarkar, Mirtra B., Brian Butler and Charles Steinfield (1995): "Intermediaries and Cybermediaries: A Continuing Role for Mediating Players in the Electronic Marketplace", Journal of Computer MediatedCommunication, 3, 1-17. [URL:http://jcmc.huji.ac.il/]

Steinfield, Charles, Robert Kraut and Alice Plummer (1995): "The Impact of Electronic Commerce on BuyerSeller Relationships", Journal of Computer Mediated-Communication, 3, 1-17. [URL:http://jcmc.huji.ac.il/]

Stewart, Thomas A. (1993): "Boom Time on the New Frontier", Fortune Magazine, Autumn, 153.

Swamidass, P.M. (1991): “Empirical Research: New Frontier in Operations Management", Academy of Management Review, 16, 4, 793-814.

Thornton, E. (1994): "Revolution in Japanese Retailing", Fortune, February, 144.

Williamson, O. (1975): Markets and Hierarchies: Analysis and Antitrust Implications, Free Press, New York.

Wiseman, Charles (1995): Strategy and Computers: Information Systems as Competitive Weapons, Dow Jones -Irwin, New York.

Yin, R.K. (1994): Case Study Research, Design and Methods, Sage Publications, Newbury Park.

Cambridge Telecom Report (1997): "Internet Commerce: Ten Key Legal and Regulatory Issues Facing the Growth", February 17.

Cambridge Work-Group Computing Report (1997): “Internet Shopping: 'Startling Increase' in Internet Shopping", March 17.

CommerceNet/Nielson Internet Demographics Survey (1997): Spring [URL:http:/www.commerce.net]

CommerceNet/Nielson Internet Demographics Survey (1996): March-April [URL:http://www.commerce.net]

Consumer Payment Preferences in the Physical World and the Virtual World (1996): Global Concepts and Bank Administration Institute, September [URL:http://www,global-concepts.com/research.html/]

Consumers Poised to Use Electronic Financial Services (1996), Newsbytes News Network, October 23,

Electronic Commerce and the Internet: A Whole New World (1997), Conning and Company

Future One Agency Universe Study (1996): Independent Insurance Agents of American, Inc. Alexandria, Virginia

Graphic, Visualisation and Useability Center (1997): “GVU Seventh Annual WWW User Survey. [URL:http://www.gvu.gatech.edu/user_surveys/]

IBM: Study Reveals Details for the Future Insurance Industry (1997), M2 PressWIRE, April 28

National Association of Insurance Commisioners (NAIC)(1997): The Marketing of Insurance Over the Internet, Draft: June 4

Net Profits. (Electronic Commerce on the Internet)(1994), The Economist, 332, July 2, 83(3)

ORACLE: Research Shows Business and IT at Loggerheads Over the Take Up of Electronic Commerce (1997), Telecomworldwire, June 17

Understanding Cyberspace. (computer networks)(survey of Technology in Finance) (1996), The Economist, 341 , October 26

World Insurance Network: World Insurance Network Sparks to Life (1996), M2 PressWIRE, March 18 


\title{
APPENDIX
}

\section{INTERVIEW GUIDE}

\section{Section I. Subject Information}

\author{
Name: \\ Position: \\ Organisation: \\ Phone Number: \\ Address: \\ City, State, Zip:
}

\section{Section II. Research Objective}

\section{General Management Ouestion:}

How is the Internet, as an electronic market, changing the role of Independent Insurance Agents in the Insurance industry?

\section{Section III. Interview Guide}

- Electronic communication effect

1. Does the Intermet allow for more information about insurance products and prices to be communicated in the same amount of time as traditional communication methods? How? Why?

2. Does the Internet allow for the costs of this communication to be decreased dramatically? How? Why?

- Electronic brokerage effect

3. Does the Internet allow agents and companies to connect a large amount of different buyers? Sellers? How? Why?

4. Does the Internet fulfil the function of assisting to match consumers with sellers of insurance? How? Why?

5. Does the Internet increase the number of alternatives of insurance products and services a consumer can consider? How? Why?

6. Does the Internet increase the quality of the alternative eventually selected? How? Why?

7. Does the Internet have the potential to decrease the cost of the entire product selection process? How? Why?

- Electronic Integration effect

8. Does the Internet facilitate the ability of producers and agents to change their business processes (sales, marketing, customer support, other)?

9. Does the Internet facilitate the ability of producers and agents to change the manner in which they use information?

- Insurance Market Structure

10. Increase or decrease in longer term relationships with consumers?

11. Increase in Value Added Partnerships?

12. Is there a move to markets, the middle, or other movement in the industry?

- Price and Product Information 
13. Does the Internet reduce buyer search costs and time for insurance products and services?

14. Does the Internet increase the ability of consumers to search for insurance products?

- Promotion of Price Competition

15. Does the Internet foster price competition in insurance products and services?

- Supplier Market Power

16. Does the Internet have the ability to reduce the market power of insurance companies?

- Network Externalities

17. Do the benefits of participation on the Internet increases as more members join?

18. Are the benefits of participation on the Internet uncertain?

19. Is the timetable for change in the Independent Agency system due to the Internet uncertain?

- Switching Costs

20. What type of switching costs are faced by agents if they change their presence and participation on the Internet?

- Capital Investment

21. Does the Internet require large amounts of initial capital investment?

22. Does the Internet offer economies of scale and scope to insurance agents?

- The Nature of Insurance Products offered by Independent Agents

23. Commodity or Differentiated Market?

24. How does the complexity of insurance products influence its presence on the Web?

25. Do specific types of insurance limit the ability of products to be generalised to a wide market?

26. How will the following influence how insurance products are applied to the Internet: (frequency of the transaction, power of buyers or suppliers, non contractible investment issues)

- Prisoner's dilemma?

27. Do agents as a whole benefit from participating on the Internet?

28. Do individual agents benefit from participating on the Intemet?

29. Will it become a strategic necessity to participate on the Internet?

- Intermediation

30. Are insurance agents threatened by the Internet? Why?

31. Is the Internet driven by consumers, agents, or companies?

- What future scenario or outlook do you see for Insurance and its distribution over an electronic market such as the Internet?

32. Generational differences?

33. Long term marketing and strategic approach? 